\title{
Protective Effects of Efonidipine, a T- and L-Type Calcium Channel Blocker, on Renal Function and Arterial Stiffness in Type 2 Diabetic Patients with Hypertension and Nephropathy
}

\author{
Hidehisa Sasaki ${ }^{1}$, Atsuhito Saiki ${ }^{2}$, Kei Endo², Noriko Ban², Takashi Yamaguchi², Hidetoshi Kawana ${ }^{2}$, \\ Daizi Nagayama², Masahiro Ohhira ${ }^{2}$, Tomokazu Oyama², Yoh Miyashita², and Kohji Shirai² \\ ${ }^{1}$ Departments of Pharmacy, Sakura Medical Center, School of Medicine, Toho University, Chiba, Japan \\ ${ }^{2}$ Departments of Internal Medicine, Sakura Medical Center, School of Medicine, Toho University, Chiba, Japan
}

\begin{abstract}
Aim: The three types of calcium channel blocker (CCB), L-, T- and N-type, possess heterogeneous actions on endothelial function and renal microvascular function. In the present study, we evaluated the effects of two CCBs, efonidipine and amlodipine, on renal function and arterial stiffness.

Methods: Forty type 2 diabetic patients with hypertension and nephropathy receiving angiotensin receptor II blockers were enrolled and randomly divided into two groups: the efonidipine group was administered efonidipine hydrochloride ethanolate $40 \mathrm{mg} /$ day and the amlodipine group was administered amlodipine besilate $5 \mathrm{mg} /$ day for 12 months. Arterial stiffness was evaluated by the cardioankle vascular index (CAVI).

Results: Changes in blood pressure during the study were almost the same in the two groups. Significant increases in serum creatinine and urinary albumin and a significant decrease in the estimated glomerular filtration rate were observed in the amlodipine group, but not in the efonidipine group. On the other hand, significant decreases in plasma aldosterone, urinary 8-hydroxy-2'-deoxyguanosine and CAVI were observed after 12 months in the efonidipine group, but not in the amlodipine group.

Conclusions: These results suggest that efonidipine, which is both a T-type and L-type calcium channel blocker, has more favorable effects on renal function, oxidative stress and arterial stiffness than amlodipine, an L-type calcium channel blocker.
\end{abstract}

J Atheroscler Thromb, 2009; 16:568-575.

Key words; T-type calcium channel blocker, Efonidipine, Oxidative stress, Diabetic nephropathy, Cardio-ankle vascular index

\section{Introduction}

In diabetic patients, hypertension is a frequent complication and accelerates cardiovascular diseases. The main purpose of blood pressure-lowering therapy in diabetic patients is to protect against the progression of nephropathy and atherosclerosis. In diabetes

Address for correspondence: Yoh Miyashita, Department of Internal Medicine, Sakura Medical Center, School of Medicine, Toho University, 564-1 Shimoshizu, Sakura-City, Chiba, 2850841, Japan

E-mail: mumon@sf6.so-net.ne.jp

Received: January 26, 2009

Accepted for publication: March 19, 2009 mellitus, angiotensin II receptor blockers (ARB) are mainly used as the first-choice antihypertensive drug. If the hypotensive effect of an ARB is insufficient, calcium channel blockers (CCB) are added in many cases. There exist three types of CCB, the L-, T- and $\mathrm{N}$-type, which have heterogeneous actions on endothelial function and renal microvascular function ${ }^{1,2)}$.

Chronic kidney disease (CKD), which includes diabetic nephropathy, is an importance risk factor for the development of cardiovascular diseases ${ }^{3,4}$. Several studies have found that CKD is a predictor of cardiovascular mortality ${ }^{5,6)}$. The importance of kidney function as a risk factor of CVD is increasingly recognized. Efonidipin, which is both a T-type and L-type CCB, 
has been reported to improve vascular endothelial dysfunction and to have a renoprotective effect ${ }^{1,2)}$.

A novel arterial stiffness parameter termed the cardio-ankle vascular index (CAVI) has been developed recently, and essentially reflects the stiffness of the aorta, femoral artery and tibial artery ${ }^{7}$.

CAVI is independent of blood pressure, and has adequate reproducibility for clinical use ${ }^{7)}$. Furthermore, no special technique is required for the measurement of CAVI. Several reports have demonstrated the usefulness of CAVI for the detection of atherosclerotic diseases ${ }^{7-10)}$.

In the present study, we evaluated the effect of two CCBs, efonidipine (a T-type and L-type CCB) and amlodipine (an L-type CCB), on renal function and CAVI in type 2 diabetic patients with nephropathy and hypertension.

\section{Subjects and Methods}

\section{Subjects}

A randomized, open study was performed. Randomization was performed with sequentially numbered, sealed envelopes using a previously determined code for the administration of either efonidipine or amlodipine. Forty type 2 diabetic patients with nephropathy and hypertension, who attended Sakura Medical Center of Toho University as outpatients and had been receiving ARB therapy with candesartan, were enrolled. They had high systolic blood pressure $(\geqq 130 \mathrm{mmHg})$ and/or high diastolic blood pressure ( $\geqq 80 \mathrm{mmHg}$ ) when measurement was performed on two different days within 4 weeks before the start of the study. Patients were excluded if they had previous cardiovascular and cerebrovascular diseases and showed high glycosylated hemoglobin ( $\mathrm{HbAlc}>7.5 \%)$. The enrolled subjects were randomly divided into two groups. One group was administered efonidipine 40 $\mathrm{mg} /$ day for 12 months (efonidipine group, $n=20$ ), and the other group was administered amlodipine $5 \mathrm{mg} /$ day for 12 months (amlodipine group, $n=20$ ). During this study, all patients maintained the same dietary and exercise therapies, and did not change medications. All subjects received nutrition education from a dietitian once every 3 months. The clinical profile of the subjects is shown in Table 1. This study was approved by the Ethics Committee of Toho University. The purpose, nature and potential risks of this study were explained to all patients, and their voluntary written consent for participation in the study and also for release of the study data was obtained before they were enrolled.
Table 1. Baseline data of the study population

\begin{tabular}{|c|c|c|}
\hline Background factor & Efonidipine & Amlodipine \\
\hline n (male/femal) & $20(14 / 6)$ & $20(12 / 8)$ \\
\hline Age (y.o) & $63.3 \pm 2.5$ & $65.5 \pm 3.0$ \\
\hline BMI $\left(\mathrm{kg} / \mathrm{m}^{2}\right)$ & $23.9 \pm 0.8$ & $24.2 \pm 0.9$ \\
\hline Systolic BP (mmHg) & $157 \pm 4.0$ & $160 \pm 3.2$ \\
\hline Diastolic BP (mmHg) & $85 \pm 1.9$ & $87 \pm 2.7$ \\
\hline Pulse rate (/min) & $74 \pm 2.6$ & $74 \pm 3.0$ \\
\hline HbA1c (\%) & $6.6 \pm 0.4$ & $6.7 \pm 0.4$ \\
\hline $\mathrm{TC}(\mathrm{mg} / \mathrm{dL})$ & $200 \pm 12$ & $202 \pm 14$ \\
\hline $\mathrm{TG}(\mathrm{mg} / \mathrm{dL})$ & $179 \pm 30$ & $161 \pm 27$ \\
\hline HDL-C (mg/dL) & $51 \pm 3.6$ & $53 \pm 4.2$ \\
\hline LDL-C (mg/dL) & $119 \pm 7.4$ & $110 \pm 9.6$ \\
\hline $\mathrm{S}-\mathrm{Cr}(\mathrm{mg} / \mathrm{dL})$ & $1.46 \pm 0.18$ & $1.46 \pm 0.17$ \\
\hline eGFR (mL/min/1.73 m²) & $46 \pm 4.9$ & $46 \pm 4.6$ \\
\hline U-Alb/Cr (mg/g Cr) & $1,338 \pm 273$ & $1,369 \pm 414$ \\
\hline 8-OHdG (ng/mg Cr) & $10.4 \pm 0.8$ & $9.8 \pm 1.0$ \\
\hline ALD (pg/mL) & $75 \pm 12$ & $78 \pm 11$ \\
\hline \multicolumn{3}{|l|}{ Blood sugar-lowering drugs } \\
\hline Sulfonyloreas (n) & 16 & 17 \\
\hline Thiazolidinedione (n) & 1 & 0 \\
\hline Alpha-glucosisase inhibitor (n) & 12 & 10 \\
\hline Biguanide (n) & 2 & 1 \\
\hline \multicolumn{3}{|l|}{ Lipid-lowering drugs (all atatins) } \\
\hline atorvastatin $(\mathrm{n})$ & 5 & 7 \\
\hline pitavastatin (n) & 5 & 4 \\
\hline Smoking (n) & 4 & 4 \\
\hline
\end{tabular}

Data are presented as the mean $\pm \mathrm{SD}$. BMI, body mass index; $\mathrm{BP}$, blood pressure; HbA1c, glycosylated hemoglobin; TC, total cholesterol; TG, triglycerides; HDL-C, HDL-cholesterol; LDL-C, LDL-cholesterol; S-Cr, serum creatinine; U-Alb/Cr, urinary albumin-to-creatinine ratio; 8-OHdG, 8-hydroxy-2'-deoxyguanosine; ALD, aldosterone; statin, HMG-CoA reductase inhibitor

\section{Measurement of Blood Pressure}

Blood pressure (BP) was measured at least twice in a sitting position in the morning after 12 hours of fasting with only candesartan and efonidipine or amlodipine at 7:30 AM.

\section{Assay of HbAlc and Serum Lipids}

Blood samples were collected in a sitting position in the morning after 12 hours of fasting. Serum was separated within 1 hour, and samples were used to measure the following chemical parameters. Stable and unstable glycosylated hemoglobin (HbA1c) fractions were measured by high pressure liquid chromatography using the Hi-Auto A1c kit (Kyoto Daiichi Kagaku, Kyoto, Japan). Data of the stable type were used in the present analysis. Total cholesterol (TC), triglyceride (TG) and low-density lipoprotein cholesterol (LDL-C) 
A

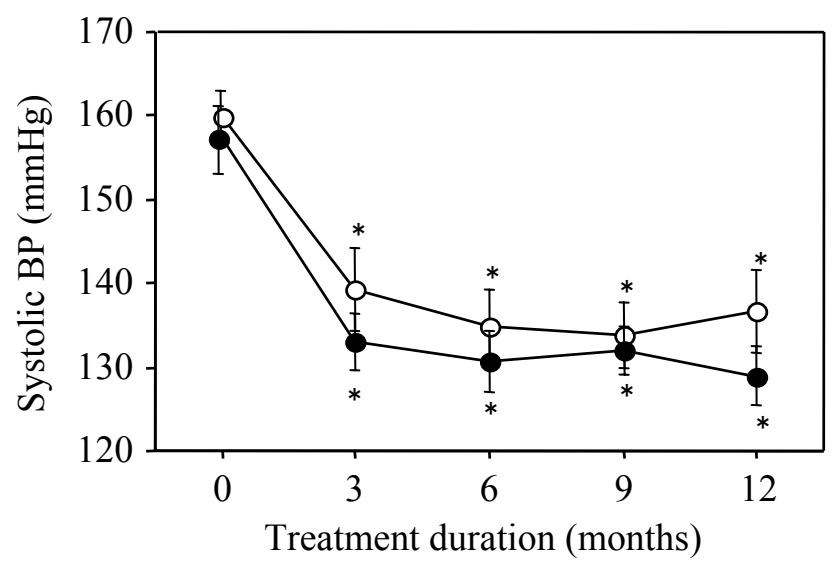

B

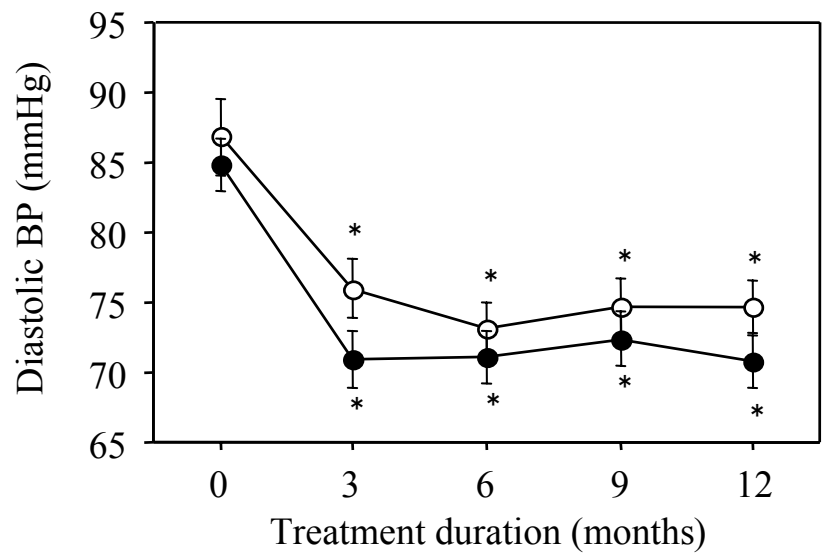

Fig. 1. Changes in systolic (A) and diastolic (B) blood pressure during treatment with efonidipine or amlodipine.

Open circle denotes amlodipine group, and closed circle denotes efonidipine group. Data are presented as the mean \pm S.D. ${ }^{*} p<0.05$ vs baseline, paired $t$-test.

were measured with an automatic analyzer (Hitachi 7150 available from Hitachi Tokyo, Japan). Highdensity lipoprotein cholesterol (HDL-C) was measured by the selective inhibition method (Daiichi Pure Chemicals, Tokyo) ${ }^{11)}$.

\section{Measurement of Kidney Function}

In this study, kidney function was assessed using serum creatinine $(\mathrm{Cr})$, urinary albumin (u-albumin) and the estimated glomerular filtration rate (eGFR). Serum creatinine was assayed enzymatically (Iatro LQ CRE; Mitsubishi Kagaku Iatron). GFR was estimated using a modified MDRD equation, as recently proposed by the Working Group of Japan Chronic Kidney Disease Initiative ${ }^{12}$ :

eGFR $\left(\mathrm{mL} / \mathrm{min}\right.$ per $\left.1.73 \mathrm{~m}^{2}\right)=0.741 \times 175 \times \operatorname{age}^{-0.203} \times$ serum creatinine $e^{-1.154}$ (if female $\times 0.742$ )

Urinary albumin was measured using the latex agglutination method and adjusted for urinary creatinine ( $\mathrm{mg}$ per $\mathrm{g} \mathrm{Cr}$ ). Microalbuminuria was defined as $\geq 30 \mathrm{mg} / \mathrm{g}$ creatinine ${ }^{13)}$.

\section{Plasma Aldosterone and Urinary 8-OHdG Analysis}

Plasma aldosterone levels (ALD) were measured using a commercial radioimmunoassay kit (SPAC-S aldosterone kit; TFB Company, Tokyo, Japan).

Urine samples were centrifuged at $800 \mathrm{~g}$ for 10 min and the supernatants were used to determine 8 hydroxy-2'-deoxyguanosine (8-OHdG) by a competitive enzyme-linked immunosorbent assay (8-Hydroxydeoxyguanosine Check; Japan Institute for the Control of Aging, Shizuoka, Japan). The monoclonal anti- body has been characterized and found to be specific for $8-\mathrm{OHdG}^{14)}$. The results were adjusted for creatinine content (ng per $\mathrm{mg} \mathrm{Cr}$ ) measured in the same urine sample.

\section{Measurement of CAVI}

CAVI was measured in the morning, after 12 hours of fasting and taking only efonidipine or amlodipine, using a VaSera CAVI instrument (Fukuda Denshi Co. Ltd., Tokyo) by the methods described previously ${ }^{7)}$. Briefly, cuffs were applied to bilateral upper arms and ankles, with the subject supine and the head held in the midline position. After resting for 10 minutes, the examinations were performed. To detect brachial and ankle pulse waves with cuffs, a low cuff pressure of 30 to $50 \mathrm{mmHg}$ was used to ensure minimal effect of cuff pressure on hemodynamics. Blood pressure was measured thereafter. CAVI was calculated by the following formula:

$$
\mathrm{CAVI}=\mathrm{a}\left\{(2 \rho / \Delta \mathrm{P}) \times \ln (\mathrm{Ps} / \mathrm{Pd}) \mathrm{PWV}^{2}\right\}+\mathrm{b}
$$

where Ps is systolic blood pressure, Pd is diastolic blood pressure, PWV is pulse wave velocity, $\Delta \mathrm{P}$ is $\mathrm{Ps}-\mathrm{Pd}, \rho$ is blood density, and a and b are constants.

Scale conversion was performed to compare CAVI with PWV (Hasegawa's method). The VaSera was equipped with both measurement and calculation systems, and automatically calculated the CAVI. The average coefficient of variation of CAVI is less than $5 \%$, which is sufficiently small for clinical usage and indicates that CAVI has good reproducibility ${ }^{7)}$. 
A

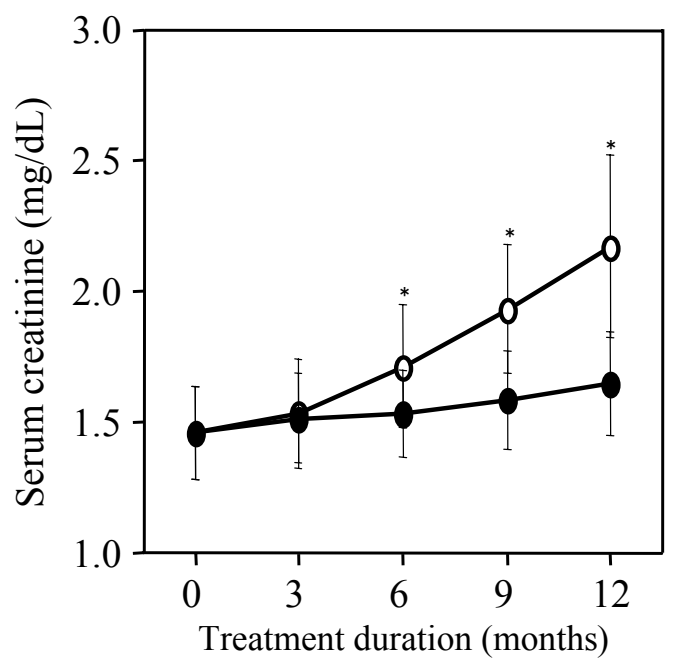

$\mathrm{B}$

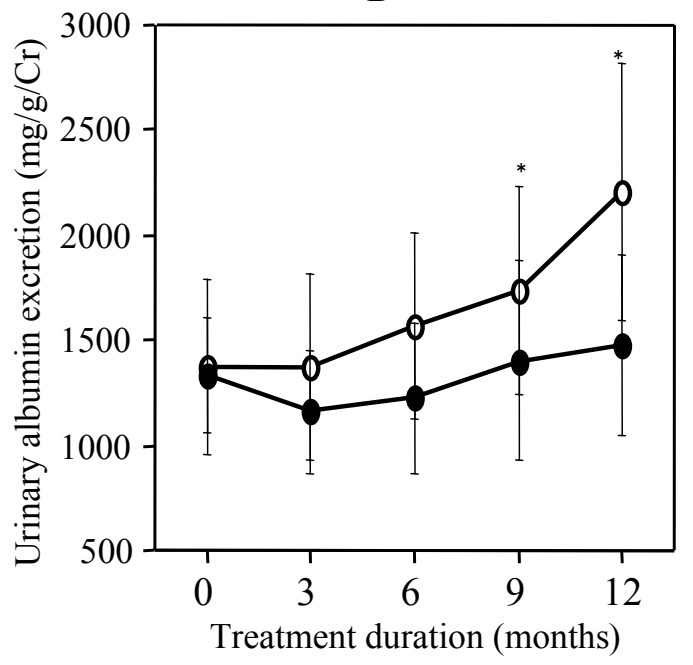

Fig. 2. Changes in serum creatinine (A) and urinary albumin (B) during treatment with efonidipine or amlodipine.

Open circle denotes amlodipine group, and closed circle denotes efonidipine group. Data are presented as the mean \pm S.D. ${ }^{*} p<0.05$ vs baseline, paired $t$-test.

\section{Statistical Analysis}

Groups were compared using Student's $t$-test or the paired $t$-test. In all comparisons, values of $p$ less than 0.05 were considered significant.

\section{Results}

\section{Changes in BP, BMI, HbA1c and Serum Lipid} Levels in Efonidipine and Amlodipine Groups

The changes of BP during this study are shown in Fig. 1. In both groups, BP decreased significantly from 3 months of $\mathrm{CCB}$ administration, and significant decreases compared to baseline were observed from 3 months through 12 months of treatment; however, no significant differences in changes of $\mathrm{BP}$ were observed between groups. During this study, no significant changes in pulse rate were observed in both groups (data not shown). Furthermore, no significant changes in BMI, HbA1c, TC, TG, HDL-C and LDL-C were observed during this study (data not shown).

\section{Effects of Efonidipine or Amlodipine Administra- tion on Renal Functions}

Changes in serum $\mathrm{Cr}$ and $\mathrm{u}$-albumin are shown in Fig. 2. Significant increases in serum $\mathrm{Cr}$ (from 6 to 12 months) and u-albumin (at 9 and 12 months) were observed in the amlodipine group, but no significant changes were observed in the efonidipine group during the entire study period. A significant decrease in

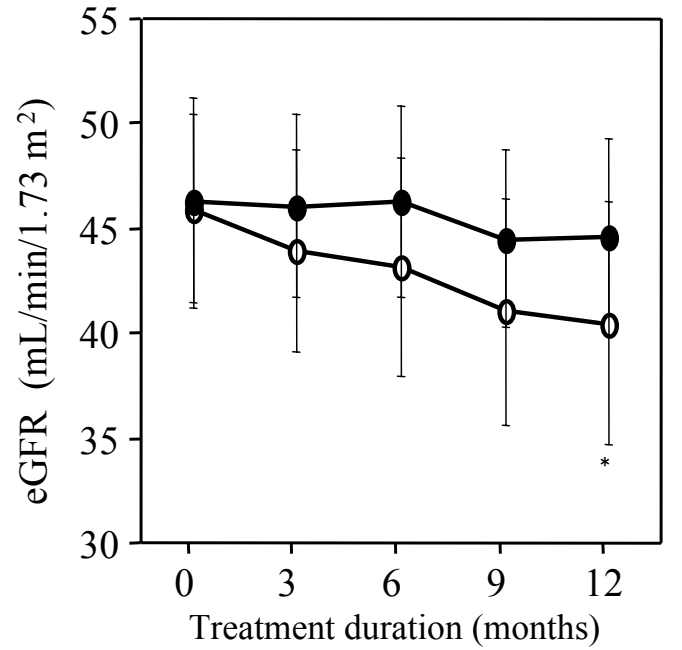

Fig. 3. Changes in estimated glomerular filtration rate (eGFR) during treatment with efonidipine or amlodipine.

Open circle denotes amlodipine group, and closed circle denotes efonidipine group. Data are presented as the mean \pm S.D. ${ }^{*} p<0.05$ vs baseline, paired $t$-test.

eGFR was found in the amlodipine group at 12 months, but no significant change was observed in the efonidipine group (Fig. 3).

ALD and 8-OHdG Levels Before and After Administration of Efonidipine or Amlodipine

The levels of plasma ALD and urinary $8-\mathrm{OHdG}$ 

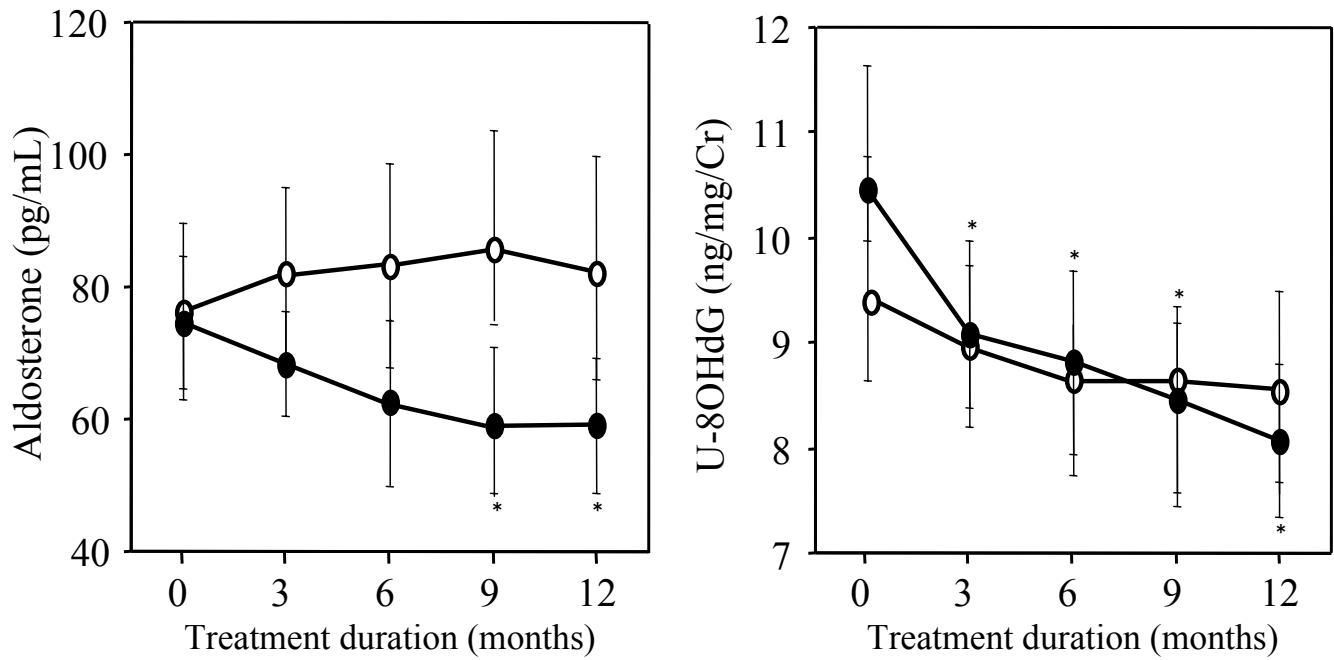

Fig. 4. Changes in plasma aldosterone (A) and urinary 8-hydroxy-2'-deoxyguanosine (8-OHdG) (B) during treatment with efonidipine or amlodipine.

Open circle denotes amlodipine group, and closed circle denotes efonidipine group. Data are presented as the mean \pm S.D. ${ }^{*} p<0.05$ vs baseline, paired $t$-test.

before and during CCB administration are shown in Fig. 4 . In the efonidipine group, significant decreases in plasma ALD were observed from 9 to 12 months of treatment while significant decreases of urinary 8-OHdG were observed from 3 through 12 months of treatment; however, no significant changes in ALD and $8-\mathrm{OHdG}$ were observed in the amlodipine group during the entire study period.

\section{Changes of CAVI in Efonidipine or Amlodipine Group}

The changes of CAVI are shown in Fig. 5. In the efonidipine group, a significant decrease in CAVI was observed after 12 months of treatment; however, no significant change in CAVI was observed in the amlodipine group.

\section{Discussion}

In the present study, serum $\mathrm{Cr}$ and u-albumin increase significantly and eGFR decreased significantly during treatment in the amlodipine group, while these parameters remained unchanged in the efonidipine group. Furthermore, significant decreases of plasma ALD, urinary 8-OHdG and CAVI were observed in the efonidipine group, but not in the amlodipine group. These results suggest that efonidipine has more favorable effects on preserving renal function, reducing oxidative stress and decreasing arterial stiffness compared to amlodipine. In this study, age and the male/female ratio were not significantly different

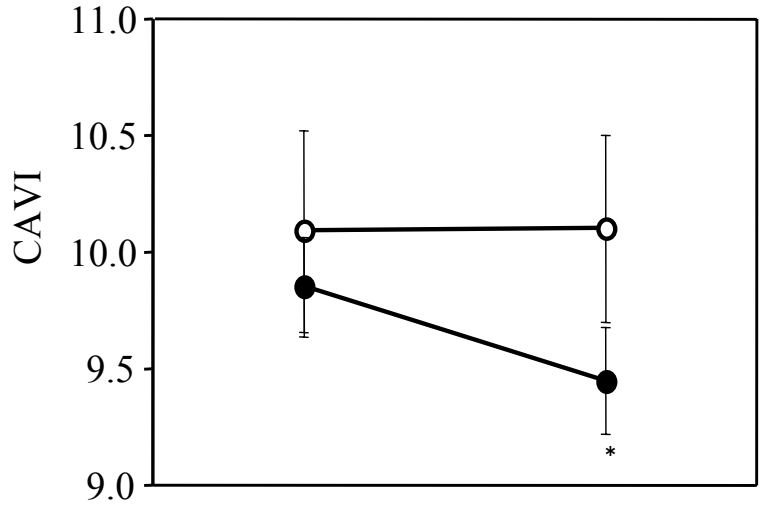

Baseline After 12-month treatment

Fig. 5. Change in CAVI before and after treatment with efonidipine or amlodipine.

Open circle denotes amlodipine group, and closed circle denotes efonidipine group. Data are presented as the mean \pm S.D. ${ }^{*} p<0.05$ vs baseline, paired $t$-test.

between groups; therefore, the results were considered not to be influenced by these factors.

Several studies indicate that T-type CCBs is superior to L-type CCBs in terms of the protective effect of renal function ${ }^{2,15,16)}$. The mechanism of this effect is generally considered to be due to the aldosteronedecreasing effect by T-type CCBs ${ }^{2,17)}$. ALD is synthesized in zona glomerulosa of the adrenal gland, and secreted mainly by calcium influx through the T-type 
calcium channel ${ }^{18,19)}$. In an in vitro study, efonidipine has been shown to inhibit aldosterone synthesis in cultured adrenocortical cells via T-type $\mathrm{CCBs}^{20}$. It has also been observed that the administration of efonidipine lowers plasma aldosterone in healthy subjects and hypertensive subjects ${ }^{21,22)}$. The ALD-decreasing potential of efonidipine is reported to result in a renoprotection effect ${ }^{2)}$. In the present study, ALD also decreased significantly in the efonidipine group; therefore, we consider that the ALD-decreasing potential of efonidipine may contribute to the reno-protection effect observed in this study. However, we also consider that the decrease of oxidative stress by efonidipine could contribute to the protection of renal function, because oxidative stress has been associated with nephropathy and other diabetic complications ${ }^{23-25)}$. In this study, significant decreases of urinary $8-\mathrm{OHdG}$ were observed in the efonidipine group, but not in the amlodipine group. This effect of efonidipine has been already reported by Oshima T. et al. ${ }^{1}$. Compound $8-\mathrm{OHdG}$ is one of the most common markers used to evaluate oxidative DNA damage, and it is a product formed by specific attack of a hydroxyl radical on $\mathrm{DNA}^{26)}$. Furthermore, several studies have demonstrated the free radical scavenging activity of CCBs in $v_{i t r o}{ }^{27-29)}$. So, we consider that efonidipine might have an improving effect on oxidative stress. This effect of efonidipine might be accounted for by a reno-protection effect. Further studies are required to clarify whether the ALD-decreasing effect and oxidative stress-reducing effect are independent or related.

Arterial stiffness is known to be associated with renal insufficiency ${ }^{30-32)}$. Mourad et al. ${ }^{31)}$ reported a negative association between creatinine clearance and carotid-femoral PWV in patients with mild renal insufficiency. Recently, Wang et al. ${ }^{32)}$ showed a stepwise increase in aortic PWV corresponding to an increase in the severity of CKD from stage 1 to 5 classified according to the KDOQI guidelines ${ }^{33)}$. These previous studies evaluated arterial stiffness using PWV, but PWV essentially depends on blood pressure ${ }^{34)}$. In the present study, CAVI was used to evaluate arterial stiffness and CAVI is independent of blood pressure $^{34)}$; therefore, we consider that arterial stiffness was evaluated more accurately in this study than in previous reports.

There are several reports about the mechanism of the association between arterial stiffness and renal insufficiency ${ }^{30,35)}$. Among them, oxidative stress and endothelial dysfunction are important mechanisms that link renal insufficiency and arterial stiffness ${ }^{36,37)}$. Increased 8-OHdG has been suggested to contribute to atherogenetic processes by inducing endothelial dysfunction ${ }^{38,39)}$. Endothelial dysfunction is associated with the accumulation of cardiovascular risk factors ${ }^{40)}$ and involves both large and small arteries, promoting progression of renal disease and contributing to acceleration of atherogenesis ${ }^{41)}$. Thus, progression of renal dysfunction may in turn induce vascular injury in large and small arteries and contribute to increased arterial stiffness.

Past study has already suggested that efonidipine could be superior to L-type CCB in improving oxidative stress and endothelial function, and that the improvement of vascular endothelial dysfunction may be due to a reduction of oxidative stress ${ }^{1}$. In the present clinical study, we demonstrated that efonidipine was superior to amlodipine in reducing $8-\mathrm{OHdG}$ and CAVI and in maintaining renal function in diabetic patients with hypertension and nephropathy. We speculate that the oxidative stress-reducing potential of efonidipine probably accounts for its favorable effects on renal function and arterial stiffness. The inhibition of T-type calcium channel by efonidipine and not by amlodipine may explain the differential effect of the two CCBs on oxidative stress. T-type calcium channels have been identified in the vasculature ${ }^{42-44)}$; however, the physiological roles and the action mechanisms of these channels in the vasculature have not yet been clarified. Therefore, it remains difficult to speculate about the precise mechanism by which efonidipine improves the state of oxidative stress.

HMG-CoA reductase inhibitors (statins) are also known to improve endothelial dysfunction and arterial stiffness ${ }^{45,46)}$. Furthermore, several reports indicate that statins improve oxidative stress ${ }^{47}, 48$. So, statins might expect to improve CAVI although there are still no reports about the effects of statins on CAVI. We report that pitavastatin may be effective to improve CAVI in patients with enhanced oxidative stress ( $J$ Atheroscler Thromb, in press). In the present study, the statin administration ratio was not significantly different between two groups; therefore, the results were considered not to be influenced by statins.

There are several limitations of this study, the most important of which was the study protocol. This study was designed for only 12 months and with a small subject pool. To clarify the different effects between efonidipine and amlodipine, a large trial over a long period is needed in the future. In addition, we evaluated oxidative stress using only $8-\mathrm{OHdG}$. This marker is not always consistent with oxidative stress in the whole body and sometimes varies widely. To evaluate the oxidative stress-reducing potential of efonidipine, other markers, such as NADPH oxidase, free radicals and superoxide dismutase, should be used. 
In summary, a T- and L-type calcium channel blocker, but not an L-type calcium channel blocker, protected renal function and improved arterial stiffness in diabetic patients with hypertension and nephropathy, probably through reducing oxidative stress. This finding is expected to be useful in the selection of CCBs when the hypotensive effect of an $\mathrm{ARB}$ is insufficient in diabetic patients with hypertension and nephropathy.

\section{References}

1) Oshima T, Ozono R, Yano Y, Higashi Y, Teragawa $H$, Miho N, Ishida T, Ishida M, Yoshizumi M, Kambe M: Beneficial effect of T-type calcium channel blockers on endothelial function in patients with essential hypertension. Hypertens Res, 2005; 28: 889-894

2) Ishimitsu T, Kameda T, Akashiba A, Takahashi T, Ohta S, Yoshii M, Minami J, Ono H, Numabe A, Matsuoka H: Efonidipine reduces proteinuria and plasma aldosterone in patients with chronic glomerulonephritis. Hypertens Res, 2007; 30: 621-626

3) Sarnak MJ, Levey AS, Schoolwerth AC, Coresh J, Culleton B, Hamm LL, McCullough PA, Kasiske BL, Kelepouris E, Klag MJ, Parfrey P, Pfeffer M, Raij L, Spinosa DJ, Wilson PW: American Heart Association Councils on Kidney in Cardiovascular Disease, High Blood Pressure Research, Clinical Cardiology, and Epidemiology and Prevention: Kidney disease as a risk factor for development of cardiovascular disease: A statement from the American Heart Association Councils on kidney in cardiovascular disease, high blood pressure research, clinical cardiology, and epidemiology and prevention. Circulation, 2003; 108: 2154-2169

4) Eknoyan G, Lameire N, Barsoum R, Eckardt KU, Levin A, Levin N, Locatelli F, MacLeod A, Vanholder R, Walker R, Wang H: The burden of kidney disease: improving global outcomes. Kidney Int, 2004; 66: 1310-1314

5) K/DOQI clinical practice guidelines for chronic kidney disease: Evaluation, classification, and stratification. Am J Kidney Dis, 2002; 39: S1-S266

6) Weiner DE, Tighiouart H, Amin MG, Stark PC, MacLeod B, Griffith JL, Salem DN, Levey AS, Sarnak MJ: Chronic kidney disease as a risk factor for cardiovascular disease and all-cause mortality: A pooled analysis of communitybased studies. J Am Soc Nephrol, 2004; 15: 1307-1315

7) Shirai K, Utino J, Otsuka K, Takata M: A novel blood pressure-independent arterial wall stiffness parameter; cardio-ankle vascular index (CAVI). J Atheroscler Thromb, 2006; 13: 101-107

8) Yambe T, Meng X, Hou X, Wang Q, Sekine K, Shiraishi Y, Watanabe M, Tamaguchi T, Shibata M, Kuwayama T, Maruyama M, Konno S, Nitta S: Cardio-ankle vascular index (CAVI) for the monitoring of the atherosclerosis after heart transplantation. Biomed Pharmacother, 2005; 59 (Suppl 1): S177-S179

9) Kubozono T, Miyata M, Ueyama K, Nagaki A, Otsuji Y, Kusano K, Kubozono O, Tei C: Clinical significance and reproducibility of new arterial distensibility index. Circ J, 2007; 71: 89-94

10) Nakamura K, Tomaru T, Yamamura S, Miyashita Y, Shirai $\mathrm{K}$, Noike $\mathrm{H}$ : Cardio-ankle vascular index is a candidate predictor of coronary atherosclerosis. Circ J, 2008; 72 : 598-604

11) Shirai K, Nema T, Hiroh Y, Itoh Y, Miyashita Y, Watanabe $\mathrm{H}$ : Clinical efficacy of the direct assay method using polymers for serum high density lipoprotein cholesterols. J Clin Lab Anal, 1992; 11: 82-86

12) Imai E, Horio $M$, Nitta $K$, Yamagata $K$, Iseki $K$, Hara $S$, Ura N, Kiyohara Y, Hirakata H, Watanabe T, Moriyama T, Ando Y, Inaguma D, Narita I, Iso H, Wakai K, Yasuda Y, Tsukamoto $\mathrm{Y}$, Ito $\mathrm{S}$, Makino $\mathrm{H}$, Hishida A, Matsuo S: Estimation of glomerular filtration rate by the MDRD study equation modified for Japanese patients with chronic kidney disease. Clin Exp Nephrol, 2007; 11: 41-50

13) American Diabetes Association: Nephropathy in diabetes, Diabetes Care, 27 (Suppl. 1) (2004), pp. S79-S83

14) Toyokuni S, Tanaka T, Hattori Y, Nishiyama Y, Yoshida A, Uchida K, Hiai H, Ochi H, Osawa T: Quantitative immunohistochemical determination of 8-hydroxy-2' deoxyguanosine by a monoclonal antibody N45.1: its application to ferric nitrilotriacetate-induced renal carcinogenesis model. Lab Invest, 1997; 76: 365-374

15) Honda M, Hayashi K, Matsuda H, Kubota E, Tokuyama H, Okubo K, Takamatsu I, Ozawa Y, Saruta T: Divergent renal vasodilator action of $\mathrm{L}$ - and T-type calcium antagonists in vivo. J Hypertens, 2001; 19: 2031-2037

16) Ohishi M, Takagi T, Ito N, Terai M, Tatara Y, Hayashi N, Shiota A, Katsuya T, Rakugi H, Ogihara T: Renal-protective effect of T-and L-type calcium channel blockers in hypertensive patients: an Amlodipine-to-Benidipine Changeover (ABC) study. Hypertens Res, 2007; 30: $797-$ 806

17) Sato A, Hayashi K, Saruta T: Antiproteinuric effects of mineralocorticoid receptor blockade in patients with chronic renal disease. Am J Hypertens, 2005; 1: 44-49

18) Barrett PQ, Isales CM, Bollag WB, McCarthy RT: $\mathrm{Ca}^{2+}$ channels and aldosterone secretion: modulation by $\mathrm{K}^{+}$ and atrial natriuretic peptide. Am J Physiol, 1991; 261: F706-719

19) Rossier MF, Ertel EA, Vallotton MB, Capponi AM: Inhibitory action of mibefradil on calcium signaling and aldosterone synthesis in bovine adrenal glomerulosa cells. J Pharmacol Exp Ther, 1998; 287: 824-831

20) Imagawa K, Okayama $S$, Takaoka $M$, Kawata $H$, Naya N, Nakajima T, Horii M, Uemura S, Saito Y: Inhibitory effect of efonidipine on aldosterone synthesis and secretion in human adrenocarcinoma (H295R) cells. J Cardiovasc Pharmacol, 2006; 47: 133-138

21) Okayama $S$, Imagawa $K$, Naya $N$, Iwama $H$, Somekawa S, Kawata H, Horii M, Nakajima T, Uemura S, Saito Y: Blocking T-type $\mathrm{Ca}^{2+}$ channels with efonidipine decreased plasma aldosterone concentration in healthy volunteers. Hypertens Res, 2006; 29: 493-497

22) Tanaka T, Tsutamoto T, Sakai H, Fujii M, Yamamoto T, Horie M: Comparison of the effects of efonidipine and amlodipine on aldosterone in patients with hypertension. Hypertens Res, 2007; 30: 691-697 
23) Baynes JW, Thorpe SR: The role of oxidative stress in diabetic complications. Curr Opin Endocrinol, 1997; 3: 277-284

24) Van Dam PS, Van Asbeck BS, Erkelens DW, Marx JJM, Gispen WH, Bravenboer B: The role of oxidative stress in neuropathy and other diabetic complications. Diabetes Metab Rev, 1995; 11: 181-192

25) Baynes JW, Thorpe SR: Role of oxidative stress in diabetic complications. Diabetes, 1999; 48: 1-9

26) Shigenaga MK, Gimeno CJ, Ames BN: Urinary 8-hydroxy2'-deoxyguanosine as a biological marker of in vivo oxidative DNA damage. Proc Natl Acad Sci USA, 1989; 86: 9697-9701

27) Mak TI, Boehme P, Weglicki WB: Antioxidant effects of calcium channel blockers against free radical injury in endothelial cells. Circ Res, 1992; 70: 1099-1103

28) Umemoto $S$, Tanaka M, Kawahara S, Kubo M, Umeji K, Hashimoto R, Matsuzaki M: Calcium antagonist reduces oxidative stress by upregulating $\mathrm{Cu} / \mathrm{Zn}$ superoxide dismutase in stroke-prone spontaneously hypertensive rats. Hypertens Res, 2004; 27: 877-885

29) Yasunari K, Maeda K, Nakamura M, Watanabe T, Yoshikawa J: Benidipine, a long-acting calcium channel blocker, inhibits oxidative stress in polymorphonuclear cells in patients with essential hypertension. Hypertens Res, 2005; 28: $107-112$

30) Safar ME, London GM, Plante GE: Arterial stiffness and kidney function. Hypertension, 2004; 43: 163-168

31) Mourad JJ, Pannier B, Blacher J, Rudnichi A, Benetos A, London GM, Safar ME: Creatinine clearance, pulse wave velocity, carotid compliance and essential hypertension. Kidney Int, 2001; 59: 1834-1841

32) Wang MC, Tsai WC, Chen JY, Huang JJ: Stepwise increase in arterial stiffness corresponding with the stages of chronic Kidney disease. Am J Kidney Dis, 2005; 45: 494-501

33) Levey AS, Eckardt KU, Tsukamoto Y, Levin A, Coresh J, Rossert J, De Zeeuw D, Hostetter TH, Lameire N, Eknoyan G: Definition and classification of chronic kidney disease: A position statement from Kidney Disease: Improving Global Outcomes (KDIGO). Kidney Int, 2005; 67: 2089-2100

34) Takaki A, Ogawa H, Wakeyama T, Iwami T, Kimura M, Hadano Y, Matsuda S, Miyazaki Y, Hiratsuka A, Matsuzaki M: Cardio-ankle vascular index is superior to brachialankle pulse wave velocity as an index of arterial stiffness. Hypertens Res, 2008; 31: 1347-1355

35) Schiffrin EL, Lipmann ML, Mann JF: Chronic kidney disease: effects on the cardiovascular system. Circulation, 2007; 116: 85-97

36) Stam F, van Guldener C, Becker A, Dekker JM, Heine RJ, Bouter LM, Stehouwer CD: Endothelial dysfunction contributes to renal function-associated cardiovascular mortality in a population with mild renal insufficiency: The Hoorn study. J Am Soc Nephrol, 2006; 17: 537-545
37) Amabile N, Guérin AP, Leroyer A, Mallat Z, Nguyen C, Boddaert J, London GM, Tedgui A, Boulanger CM: Circulating endothelial microparticles are associated with vascular dysfunction in patients with end-stage renal failure. J Am Soc Nephrol, 2005; 16: 3381-3388

38) Fan J, Watanabe T: Inflammatory reactions in the pathogenesis of atherosclerosis. J Atheroscler Thromb, 2003; 10: 63-71

39) Lei YC, Hwang JS, Chan CC, Lee CT, Cheng TJ: Enhanced oxidative stress and endothelial dysfunction in streptozotocin-diabetic rats exposed to fine particles. Environ Res, 2005; 99: 335-343

40) Tsuchiya K, Nakayama C, Iwashima F, Sakai H, Izumiyama H, Doi M, Hirata Y: Advanced endothelial dysfunction in diabetic patients with multiple risk factors; importance of insulin resistance. J Atheroscler Thromb, 2007; 14: 303-309

41) Endemann DH, Schiffrin EL: Endothelial dysfunction. J Am Soc Nephrol, 2004; 15: 1983-1992

42) Chen CC, Lamping KG, Nuno DW, Barresi R, Prouty SJ, Lavoie JL, Cribbs LL, England SK, Sigmund CD, Weiss RM, Williamson RA, Hill JA, Campbell KP: Abnormal coronary function in mice deficient in $\alpha 1 \mathrm{H} \mathrm{T-type} \mathrm{Ca}^{2+}$ channels. Science, 2003; 302: 1416-1418

43) Vanbavel E, Sorop O, Andreasen D, Pfaffendorf M, Jensen BL: Role of T-type calcium channels in myogenic tone of skeletal muscle resistance arteries. Am J Physiol Circ Physicl, 2002; 283: H2239-H2243

44) Nilius B, Prenen J, Kamouchi M, Viana F, Voets T, Droogmans G: Inhibition by mibefradil, a novel calcium antagonist, of $\mathrm{Ca}^{2+}$ - and volume-activated $\mathrm{Cl}$ - channels in macrovascular endothelial cells. Br J Pharmacol, 1997; 121: 547-555

45) Shinohara K, Shoji T, Kimoto E, Yokoyama H, Fujiwara S, Hatsuda S, Maeno T, Shoji T, Fukumoto S, Emoto M, Koyama H, Nishizawa Y: Effect of atorvastatin on regional arterial stiffness in patients with type 2 diabetes mellitus. J Atheroscler Thromb, 2005; 12: 205-210

46) Hongo M, Tsutsui $H$, Mawatari E, Hidaka $H$, Kumazaki S, Yazaki Y, Takahashi M, Kinoshita O, Ikeda U: Fluvastatin improves arterial stiffness in patients with coronary artery disease and hyperlipidemia: a 5-year follow-up study. Circ J, 2008; 72: 722-728

47) Matsuo T, Iwade K, Hirata N, Yamashita M, Ikegami $H$, Tanaka N, Aosaki M, Kasanuki H: Improvement of arterial stiffness by the antioxidant and anti-inflammatory effects of short-term statin therapy in patients with hypercholesterolemia. Heart Vessels, 2005; 20: 8-12

48) Endo K, Miyashita Y, Sasaki H, Ebisuno M, Ohira M, Saiki A, Koide N, Oyama T, Takeyoshi M, Shirai K: Probucol and atorvastatin decrease urinary 8-hydroxy-2'deoxyguanosine in patients with diabetes and hypercholesterolemia. J Atheroscler Thromb, 2006; 13: 68-75 